\title{
Implications for pharmaceutical companies and clinicians from the Bayer v NHS judgement: an increasing budgetary focus for both
}

\author{
Hanna I. Hyry ${ }^{1} \cdot$ Jonathan C. P. Roos ${ }^{2}$ \\ Received: 25 October 2018 / Accepted: 7 November 2018 / Published online: 29 November 2018 \\ (c) The Royal College of Ophthalmologists 2018
}

\begin{abstract}
The English High Court recently dismissed the Bayer pharmaceutical company's challenge against a regional clinical commissioning group's policy allowing NHS Trusts to use a cheaper, but unlicensed, alternative to a sight preserving eye treatment. This makes sober reading for companies marketing "on-label" sales of medicines which are more expensive than off-label or unlicensed alternatives. Unsurprisingly, Bayer has sought to appeal the judgement. The Court has also created legal uncertainty for the NHS: the test for lawfulness is shifted from the Clinical Commission Groups and their policies to individual trusts which must ensure that every unlicensed use is lawful. This could generate legal action against NHS Trusts and ironically drive up costs for the public purse. What is clear is that the Court's conclusions were heavily influenced by fiscal constraints which it accepted as a legitimate counterweight to the commercial interests of pharmaceutical companies. It also appears to establish in law the duty for doctors to have concern for the wider societal costs of prescribed treatments. This article summarises this complex judgement and offers advice for navigating the increasing focus on limited budgets, both for companies and physicians.
\end{abstract}

\section{Introduction: summary of the claim}

The case concerns a judicial review claim by Bayer Plc ("Bayer") and Novartis Pharmaceuticals UK Ltd ("Novartis") [1] which challenged the lawfulness of a policy adopted by the defendant Clinical Commissioning Groups ("CCGs") in Northern England. The policy concerns treatment of Age-Related Macular Degeneration and concerns three different drugs for its neovascular form ("wet AMD") which can lead to a severe loss of vision and blindness without early treatment. These are:

\footnotetext{
Hanna I. Hyry

hannaihyry@gmail.com

$\triangle$ Jonathan C. P. Roos

jcpr2@cam.ac.uk

drjonathanroos@gmail.com

1 Dispute Resolution Lawyer and Solicitor of England and Wales, Higher Rights of Audience to the UK Supreme Court, London, UK

2 Ipswich Hospital NHS Trust, Heath Road, Ipswich, UK
}

a. Eylea (aflibercept), for which Bayer holds marketing authorisation for ophthalmic use,

b. Lucentis (ranibizumab), with marketing authorisation held by Novartis for ophthalmic use, and in which Roche indirectly has a stake, and

c. Avastin (bevacizumab), for which Roche holds marketing authorisation for colorectal cancer and other non-ophthalmic uses. Roche has not applied for marketing authorisation for the ophthalmic use of Avastin despite multiple large clinical trials showing it to be as clinically effective as Lucentis but at a fraction of the cost $[2,3]$.

The CCGs' policy states that Avastin will be offered by NHS Trusts and GPs to certain patients with wet AMD "as the preferred treatment option". The policy was advisory rather than mandatory, and was adopted because of the difference in cost: Avastin costs around $£ 28$ per injection, Eylea $£ 816$ per injection, and Lucentis $£ 551$ per injection, resulting in approximately $£ 43$ million of cumulative savings over 5 years, without a "clinically significant difference between Avastin and Lucentis in terms of safety or effectiveness" [4]. 


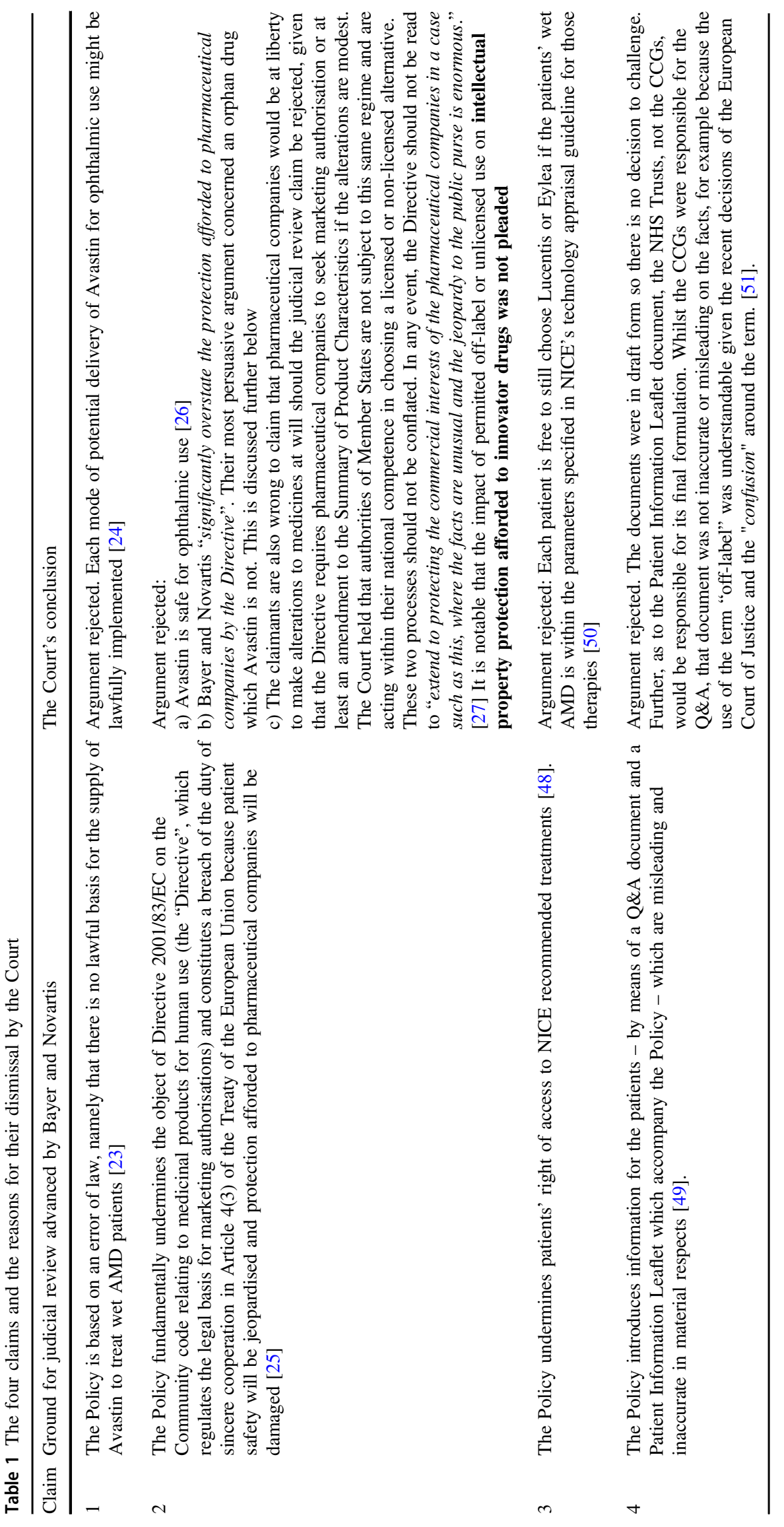




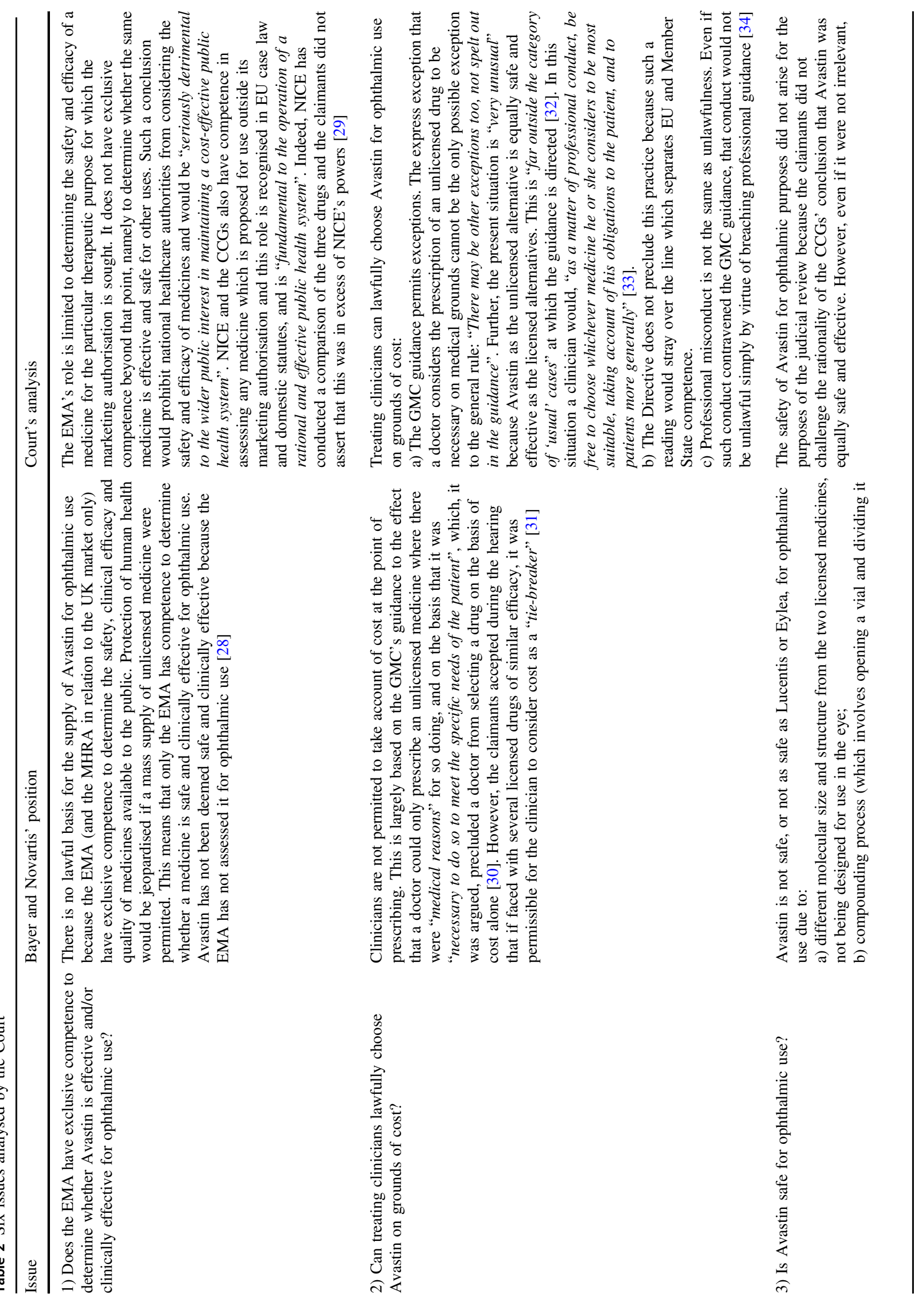




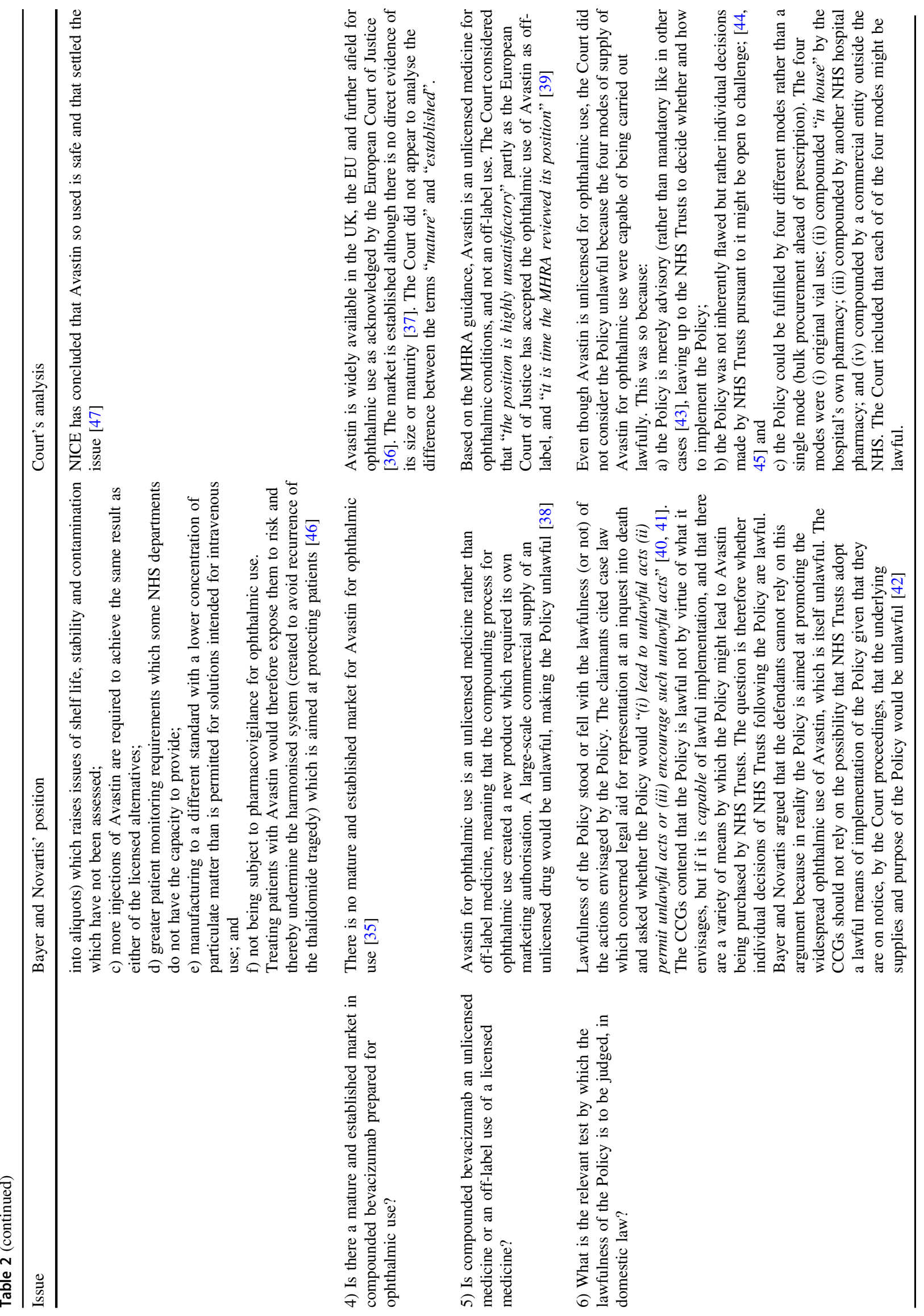




\section{Summary of judgement}

The High Court rejected the judicial review claim. Mrs Justice Whipple broke the analysis into six questions considered in Table 2. On that basis, she rejected each of the claimants' four grounds of judicial review (see Table 1). As a headline observation, the judgement hangs together rather loosely with few cross-references between the three parts of the judgement: (i) the legal framework, (ii) the Court's lengthy 99 paragraph consideration of the six questions it identified (see Table 2), and (iii) on that basis, the rather summary dismissal in 18 paragraphs of some of Bayer and Novartis' complaints (see Table 1). It will therefore be interesting to see whether an appeal will be permitted. And if so, will the Medicines and Healthcare products Regulatory Agency (MHRA) make submissions on whether Avastin should be considered off-label (used for an indication other than for what is has marketing authorisation for) or unlicensed (the process of administration has created a new product which requires a marketing authorisation) when in ophthalmic use [5].

\section{Zeitgeist: "enormous jeopardy" to the public purse}

Particularly noteworthy is the Court's reference to the "enormous" "jeopardy to the public purse" which appears to have influenced its analysis heavily:

"I cannot accept that the [marketing authorisation] scheme and purpose of the Directive [2001/83/EC regulating marketing authorisations] should extend to protecting the commercial interests of the pharmaceutical companies in a case such as this, where the facts are unusual and the jeopardy to the public purse is enormous. That would upset the careful balances in the Directive, between the commercial interests of pharmaceutical companies on the one hand and the public benefit safeguarded by the State on the other, and between the centralised competence of the [European Medicines Agency (EMA)] on the one hand and the competence conferred on national authorities on the other." [6]

The "unusual" element referred to was "the extensive material to show that the cheaper but unlicensed alternative (Avastin) is of equivalent clinical effectiveness and safety as the licenced alternatives" [7].

Unusual was also the conflicting guidance: on the one hand, the Royal College of Ophthalmologists supports both Avastin and Lucentis being made available in the UK for ophthalmic use, the GMC expects clinicians to make good use of resources and NICE demands cost-effective treatments. On the other hand, the MHRA's guidance is that Avastin's division into smaller doses for ophthalmic use involves a manipulation resulting in an "unlicensed medicine" which the GMC requires doctors to avoid if a licensed medication is available [8]. Unsurprisingly, the Court urged the MHRA to review its position [9].

The future implication of this judgement could be signficant; for how "unusual" will it be in the future to have two treatments with equal clinical effectiveness and safety for a given indication, especially given the push to encourage more competition from generics and bio-similars? Rather, one expects the availability of off-label/unlicensed alternatives to become the new norm.

The debate has undeniably shifted over the last decade: from a focus on ensuring innovation, to enabling access to important medicines, to budget constraints. The Court appeared to work hard to conclude that even a policy in favour of an unlicensed (and not just off-label) treatment might be lawful, and to adopt a reading of EU law which allowed it to reach what the CCGs celebrated as a "common sense" conclusion that the cheaper and equally safe and effective drug should be made available [10].

\section{Passing the buck to NHS trusts; a low bar for lawfulness}

Significant is also the Court's conclusion that the lawfulness of a policy is not determined by the actions envisaged by the CCG's Policy, but rather whether it is capable of lawful implementation by NHS Trusts. Because the CCG Policy was advisory rather than mandatory, the Court focussed on the legality of implementation by trusts, rather than lawfulness of the CCG Policy. The Court did not sympathise with the rather compelling argument that the aim of the Policy was to increase the ophthalmic use of Avastin in the NHS by the CCG.

The Court tried to help trusts to use unlicensed treatments by saying that they "might" rather than must be lawful, depending on the intricacies of different composition processes (see Table 2, issue 6). This creates room to manoeuvre for NHS Trusts by setting a low bar for what is "lawful" but also creates a high level of uncertainty. For they must now try to map out all possible ways of supply, and reflect-in light of the judgement-whether those might be lawful. NHS Trusts should also expect to be defendants in court as a result of these actions: the Court noted that "individual decisions made pursuant to it [by NHS Trusts] may be capable of challenge in due course" [11]. It would be an ironic outcome that budget constraints lead to more judicial review claims against NHS Trusts funded out of the same or related limited budgets. It may also force companies to allocate more of their budgets to judicial review litigation. 


\section{What are the options open to companies?}

\section{A) Recalibrate the price}

The fiscal focus means that companies charging high prices compared to off-label/unlicensed products will face significant headwind. They may wish to consider whether a lower price means less resistance because the impact on the public purse is less "enormous". Presumably the lower the price differential between the on-label and off-label/unlicensed treatment, the less contentious the issue becomes. Although not part of this test, one might have regard to the retail price in other EU countries to see if the difference is lower (comparator prices have featured in competition authorities' analysis of pharmaceutical pricing) [12]. Such careful calibration could help escape expensive multi-front litigation.

\section{B) Justify the price}

Expensive proceedings aside, a judicial limelight and pronouncements about "enormous" price differences are not optimal publicity. The fiscal focus is unlikely to ease. "Onlabel sellers" may thus wish to consider alternative strategies to expensive court action. These may include enhanced R\&D to ensure that the on-label product is superior in safety and efficacy to off-label and unlicensed alternatives, or even offering the on-label alternative on a compassionate use basis free of charge until a sustainable price is set. An EUcommissioned study has identified a "black box of pricing" with little information about the cost of development of drugs published by companies to justify prices [13]. Greater transparency could potentially justify higher pricing.

\section{C) Become an orphan}

The EU orphan regulation 141/2000 offers additional and valuable protection. The Court concluded that the claimants "significantly overstate" the protection afforded to companies [14]. The High Court concluded that "Avastin is not an orphan drug, and it is no surprise that it does not benefit from the same level of protection" [15]. This suggests that the Court might more readily limit national authorities' licence to assess safety and efficacy of off-label and unlicensed alternatives where the "on-label" medicine is protected by orphan marketing exclusivity reserved for rare diseases. This affirms that orphan marketing exclusivity continues to provide valuable protection from competition.

\section{D) Brexit barter}

The shape of Brexit will determine which of the EU statutes and case law-if any-relied on in the judgement will continue to be in force. Uncertainty is the word, and the question of lawfulness of a policy recommending off-label/ unlicensed medication may well end up before the Court again. It will certainly not be the only contentious legal issue after Brexit and given resulting budgetary constraints may become even more acute. Companies are therefore encouraged to seek out alternative third ways to settle on a sustainable price.

\section{Implications for clinicians}

One of the central questions in the judgement is whether doctors can lawfully prescribe bevacizumab for wet AMD on grounds of cost. The Court answered the question in the affirmative (see Table 2, issue 2).

In short, a doctor is entitled to prescribe bevacizumab for ophthalmic use because it is equally safe and effective. The rule may cause anxiety in case of other conditions, where an individual doctor has to try to assess whether the unlicensed medicine in question is as safe and effective as its licensed alternatives as in bevacizumab's case, without the benefit of clarification by the Court and the large randomised clinical controlled trials which exist for bevacizumab and its rivals.

The question also brings into focus the role of clinicians as budgetary gatekeepers. The GMC Guidance dictates inter alia that "doctors must... use resources efficiently for the benefit of patients and the public" [16]. The Court noted that the GMC guidance [17] "considered overall, positively requires treating clinicians to take cost into account as an element of good medical practice. That obligation does not stop simply because an unlicensed drug is under consideration. Having regard to resources is an enduring requirement, which touches on every decision which a clinician makes" [18].

In this statement, the Court appears to accept the principle that a doctor's duty includes taking cost into account. The statement is significant because the Court does not consider legal authorities for this principle. It cites as the source the GMC's guidance, but that guidance does not cite legal authorities in support on this point. Further, the GMC's guidance itself is not legally binding: the Court notes that a breach of GMC guidance may constitute professional misconduct but does not amount to breaking the law [19]. However, the Court's statement that "having regard to resources is an enduring requirement, which touches on every decision which a clinician makes", seems to give the professional obligation legal force, given that this principle is now part of English case law.

The Court also noted that doctors should, "as a matter of professional conduct, be free to choose whichever medicine he or she considers to be most suitable, taking account of his obligations to the patient, and to patients more generally" [20].

The medical community should pause to debate the extent and scope of the budgeting obligation accepted by the Court. The 'positive requirement' to consider cost, the Court's words "patients more generally" and the GMC's reference to "the benefit... of the public" are significant. A 
clinician's traditional obligation in the Hippocratic oath is on a micro-level to the patient at hand: "[i]nto whatsoever houses I enter, I will enter to help the sick." [21] It is, notably, not a macro-level duty to map out the houses in the area and to decide who should be cared for and with what resource. However, the Court's analysis appears to introduce such an obligation on a larger scale.

This may reflect a fundamental change in our understanding of doctors' duties. A doctor traditionally asks themselves: "Which available treatment regime is in the best clinical interest of this patient?" The new approach introduces a secondary question: "Having decided that the patient would benefit most from treatment X, should I nevertheless withhold the treatment given that "patients more generally" would benefit from the cost saving that I introduce by declining to treat this patient?" This seems a relatively new expectation for which many doctors may feel ill prepared, not having been trained in priority setting in medical school.

More importantly, the revised question leads to potentially unsound decisions. Doctors do not have visibility over priority setting and would therefore be making the decision to withhold treatment for Patient A without knowing who is in the pool of patients at large, how their clinical needs are best served, and exactly how the saving would help each of them. In short, a global obligation to consider cost, coupled with only micro-level visibility over the other patients being considered.

The Royal College of Ophthalmologists summarising the Avastin judgement highlights the difficulty: the wish to see Avastin being used as a treatment for wet AMD "is driven by a recognition that their departments are significantly underresourced", but "[i]n reality, there is no mechanism in place that will guarantee that money saved will be reinvested in ophthalmology services" (emphasis added) [22].

This recognition highlights that doctors appear to be expected to save costs but simultaneously have no visibility over the alternative use of the savings. There is force in the Court's conclusion that, when deciding between two equally safe and effective medicines, a doctor is entitled to have regard to cost as a "tie-breaker". Much less attractive is the possibility that a doctor should advocate for a less safe and effective treatment because it is less expensive than an alternative. We need a clear and comprehensive review of the legal obligations and rights of doctors in this field, and whether such obligations should be accompanied with the right to decide where savings are directed.

\section{Conclusion}

The judgement has profound strategic implications for the pharmaceutical sector going forward. Equally, it appears to represent a legal change to the duties of a doctor-with more legal force than the "guidance" issued by the GMC. Companies and clinicians must be mindful of pricing and resource use in the decisions they will make going forward. Although the Court's scope was limited in view by the "unusual" situation of having two equally effective and safe drugs at different price levels, emerging generics and biosimilars, and personalisation of medicine, will mean that this situation is likely to become more common. The judgement will thus become even more widely applicable.

\section{License}

The corresponding author has the right to grant on behalf of all authors and does grant on behalf of all authors, an exclusive license on a worldwide basis to permit this article to be published

\section{Guarantor}

Ms. Hyry serves as guarantor of this work. It is an honest, accurate, and transparent account of the judgment being analysed. No important aspects of the study have been omitted.

Author contributions Both authors conceived of the idea for this study and have contributed to the data gathering, analysis and writing.

\section{Compliance with ethical standards}

Conflict of interest JCPR prescribes anti-VEGF therapies in the NHS and HIH is a dispute resolution lawyer with a particular interest in pharmaceutical law and orphan drugs.

\section{References}

1. Bayer Plc anor v NHS Darlington CCG et al. [2018] EWHC 2465 (Admin).

2. Chakravarthy U, Harding SP, Rogers CA, Downes SM, Lotery AJ, Culliford LA, Reeves BC. IVAN study investigators. Alternative treatments to inhibit VEGF in age-related choroidal neovascularisation: 2-year findings of the IVAN randomised controlled trial. Lancet. 2013;382:1258-67.

3. CATT Research Group, Martin DF, Maguire MG, Ying GS, Grunwald JE, Fine SL, Jaffe GJ. Ranibizumab and bevacizumab for neovascular age-related macular degeneration. N Engl J Med. 2011;364:1897-908.

4. Bayer Plc anor v NHS Darlington CCG et al. [2018] EWHC 2465 (Admin), paras 3, 28, 62, 145-146. The statement regarding equal safety and efficacy was made by the RCO, NICE, GMC and North of England Treatment Advisory Group and cited the IVAN \& CATT studies (see ref. $2 \& 3$ above respectively). 
5. Bayer Plc anor v NHS Darlington CCG et al. [2018] EWHC 2465 (Admin), see Table 2, issue 5.

6. Bayer Plc anor v NHS Darlington CCG et al. [2018] EWHC 2465 (Admin), para 245.

7. Bayer Plc anor v NHS Darlington CCG et al. [2018] EWHC 2465 (Admin), para 151(i)(c).

8. Bayer Plc anor v NHS Darlington CCG et al. [2018] EWHC 2465 (Admin), paras 18 and 32

9. Bayer Plc anor v NHS Darlington CCG et al. [2018] EWHC 2465 (Admin), para 191.

10. Ives L NHS to save 'hundreds of millions' in landmark drug ruling in England. BBC. 21 September 2018.

11. Bayer Plc v NHS Darlington CCG [2018] EWHC 2465 (Admin), para 196.

12. See e.g. Flynn and Pfizer v Competition and Markets Authority [2018] CAT 11.

13. Picavet E, Morel T, Cassiman D, Simoens S. Shining a light in the black box of orphan drug pricing. Orphanet $\mathrm{J}$ Rare Dis. 2014;9:62.

14. The Court dismissed the comparison with another case where the General Court decided that the Commission should not have granted a marketing authorisation for a drug called Kolbam, in circumstances where that authorisation included use for certain therapeutic indications which were already within the exclusive orphan marketing authorisation for a different drug, called Orphaco (para 242).

15. Bayer Plc anor v NHS Darlington CCG et al. [2018] EWHC 2465 (Admin), para 242.

16. Bayer Plc anor v NHS Darlington CCG et al. [2018] EWHC 2465 (Admin), para 60.

17. General Medical Council, Leadership and management for all doctors, January 2012. https://www.gmc-uk.org/-/media/ documents/Leadership_and_management_for_all_doctors English_1015.pdf_48903400.pdf

18. Bayer Plc anor v NHS Darlington CCG et al. [2018] EWHC 2465 (Admin), para 151(iii)

19. Bayer Plc anor v NHS Darlington CCG et al. [2018] EWHC 2465 (Admin), para 153(ii).

20. Bayer Plc anor v NHS Darlington CCG et al. [2018] EWHC 2465 (Admin), para 152

21. Hippocrates of Cos. The Oath. Loeb Class Libr. 1923;147:298-9. https://www.loebclassics.com/view/hippocrates_cos-oath/1923/ pb_LCL147.299.xml;jsessionid $=83$ C1301826E0987F603D173452C82083Accessed 20 Oct 2018.

22. Burdon M Avastin Update - briefing from The Royal College of Ophthalmologists. https://www.rcophth.ac.uk/wp-content/uploa ds/2018/10/Avastin-briefing_1.pdf?_cldee $=$ ZHJqb25hdGhhbnJvb3NAZ21haWwuY29t\&recipientid=conta ct-720818541856e41193f900155d000f0d-a bef2f0277bb481995e60832994a43cb\&esid=efe755cc-1dcee811-94ac-00155de1ae00\&urlid =1

23. Bayer Plc anor v NHS Darlington CCG et al. [2018] EWHC 2465 (Admin), paras 5, 239-260.

24. Bayer Plc anor v NHS Darlington CCG et al. [2018] EWHC 2465 (Admin), para 239; see also Table 2, issue 6.
25. Bayer Plc anor v NHS Darlington CCG et al. [2018] EWHC 2465 (Admin), paras 5, 240.

26. Bayer Plc anor v NHS Darlington CCG et al. [2018] EWHC 2465 (Admin), see Table 2, issue 3.

27. Bayer Plc anor v NHS Darlington CCG et al. [2018] EWHC 2465 (Admin), paras 242-5.

28. Bayer Plc anor v NHS Darlington CCG et al. [2018] EWHC 2465 (Admin), paras 5, 140-1.

29. Bayer Plc anor v NHS Darlington CCG et al. [2018] EWHC 2465 (Admin), paras 143-5.

30. Bayer Plc anor v NHS Darlington CCG et al. [2018] EWHC 2465 (Admin), para 148.

31. Bayer Plc anor v NHS Darlington CCG et al. [2018] EWHC 2465 (Admin), para 149.

32. Bayer Plc anor v NHS Darlington CCG et al. [2018] EWHC 2465 (Admin), para 151.

33. Bayer Plc anor v NHS Darlington CCG et al. [2018] EWHC 2465 (Admin), para 152.

34. Bayer Plc anor v NHS Darlington CCG et al. [2018] EWHC 2465 (Admin), para 153.

35. Bayer Plc anor v NHS Darlington CCG et al. [2018] EWHC 2465 (Admin), para 163.

36. E.g. Case C-535/11 Novartis Pharma GmbH v Apozyt GmbH EU: C:2013:226.

37. Bayer Plc anor v NHS Darlington CCG et al. [2018] EWHC 2465 (Admin), paras 164-77.

38. Bayer Plc anor v NHS Darlington CCG et al. [2018] EWHC 2465 (Admin), paras 182-184, 193.

39. Bayer Plc anor v NHS Darlington CCG et al. [2018] EWHC 2465 (Admin), para 186-191.

40. Gillick v West Norfolk and Wisbech HA and anor [1986] 2 AC 112.

41. R (Letts) v Lord Chancellor (ECHR intervening) [2015] EWHC 402 (Admin).

42. Bayer Plc anor v NHS Darlington CCG et al. [2018] EWHC 2465 (Admin), paras 193-195.

43. R (Letts) v Lord Chancellor (ECHR intervening) [2015] EWHC 402 (Admin)

44. R (Tabbakh) v Staffordshire and West Midlands Probation Trust and Anor [2014] EWCA Civ 827.

45. R (Refugee Legal Centre) v Secretary of State for the Home Department [2004] EWCA Civ 1481.

46. Bayer Plc anor v NHS Darlington CCG et al. [2018] EWHC 2465 (Admin), paras 154-6.

47. Bayer Plc anor v NHS Darlington CCG et al. [2018] EWHC 2465 (Admin), paras 159-60.

48. Bayer Plc anor v NHS Darlington CCG et al. [2018] EWHC 2465 (Admin), paras 5, 247.

49. Bayer Plc anor v NHS Darlington CCG et al. [2018] EWHC 2465 (Admin), paras 5, 251-252.

50. Bayer Plc anor v NHS Darlington CCG et al. [2018] EWHC 2465 (Admin), paras 249-250.

51. Bayer Plc anor v NHS Darlington CCG et al. [2018] EWHC 2465 (Admin), paras 255-257. 